\title{
Preoperative elective transjugular intrahepatic portosystemic shunt for cirrhotic patients undergoing abdominal surgery
}

\author{
Deepanshu Jain ${ }^{a}$, Ejaz Mahmood ${ }^{b}$, Maria V-Bandres ${ }^{b}$, Eyob Feyssa ${ }^{a}$
}

Albert Einstein Medical Center, Philadelphia, PA, USA

\begin{abstract}
Despite improvements in the surgical techniques, anesthesia and intensive care, abdominal surgery in patients with cirrhosis remains a challenge. Transjugular intrahepatic portosystemic shunt (TIPS) has been used to manage complications of portal hypertension. Preoperative TIPS (prophylactic) can theoretically improve outcomes in this population. Seven original studies were identified with 24 patients who underwent prophylactic TIPS before abdominal surgery. No perioperative mortality or major abdominal bleeding attributable to portal hypertension was reported for this cohort. One patient had poor wound healing post surgery (4.2\%), one had right heart failure (4.2\%), and five developed hepatic encephalopathy (20.8\%) post surgery. More evidence is needed to optimize the timing of surgery post TIPS and the selection of an appropriate stent size to further decrease the associated morbidity. Overall, the decision for prophylactic TIPS placement for cirrhotic patients undergoing abdominal surgery needs individualization to allow its safe use with concomitant improvement in perioperative morbidity.
\end{abstract}

Keywords Prophylactic transjugular intrahepatic portosystemic shunt, cirrhosis, portal hypertension, abdominal surgery

Ann Gastroenterol 2018; 31 (3): 1-9

\section{Introduction}

By virtue of the pathophysiology of cirrhosis, in addition to the contribution from its etiologic agent (hepatitis $\mathrm{B} / \mathrm{C}$, alcohol, autoimmune), the cirrhotic patient is at risk for encephalopathy, ascites (infections and poor wound healing), increased pressures in portal circulation (bleeding), renal dysfunction (hepatorenal syndrome), cardiac dysfunction (high cardiac output leading to cirrhotic cardiomyopathy), electrolyte disturbances (hyponatremia), respiratory issues (portopulmonary hypertension, hepatic hydrothorax, hepatopulmonary syndrome), malnutrition (poor wound

a Division of Gastroenterology and Hepatology, Department of Digestive Diseases and Transplantation (Deepanshu Jain, Eyob Feyssa); 'Internal Medicine Department (Ejaz Mahmood, Maria V-Bandres), Albert Einstein Medical Center, Philadelphia, PA, USA

Conflict of Interest: Dr. Feyssa is on a speaking bureau for Gilead, Merck, AbbVie and Valeant. He is also a consultant for Gilead and AbbVie

Correspondence to: Deepanshu Jain, MD, Division of Gastroenterology and Hepatology, Department of Digestive Diseases and

Transplantation, Albert Einstein Medical Center, 5401 Old York Road, Philadelphia, PA19141, USA, e-mail: deepanshu.jain.25@gmail.com

Received 2 November 2017; accepted 12 February 2018; published online 15 March 2018

DOI: https://doi.org/10.20524/aog.2018.0249 healing), and poor tolerance to stress (surgery). One or more of these factors are together responsible for poor surgical outcomes in this population. Abdominal surgery in patients with cirrhosis is associated with higher rates of morbidity and mortality [1]. Despite improvements in the surgical techniques, anesthesia and intensive care, major abdominal surgery in patients with cirrhosis remains a challenge. The mortality can be as high as $50 \%$ in emergent cases [2]. The mortality and morbidity risk correlates with the ChildTurcotte-Pugh (CTP) class of cirrhosis [3]. Consequently, abdominal surgery may be contraindicated in some patients with cirrhosis and portal hypertension who would otherwise have been candidates for potentially curative surgical procedures.

Transjugular intrahepatic portosystemic shunt (TIPS) has been used to manage complications of portal hypertension, including bleeding esophageal varix, refractory ascites and hepatic hydrothorax [4]. Preoperative TIPS can theoretically improve outcomes in patients with cirrhosis and portal hypertension undergoing abdominal surgery by decompressing the varices and resolution of ascites, thus decreasing bleeding (perioperative), improving wound healing, and minimizing the infection risk.

In this review article, we have summarized the single-center reports describing the prophylactic use of TIPS in patients undergoing major abdominal surgery. 


\section{Materials and methods}

An extensive English literature search was performed, using PubMed and Google Scholar, to identify the peer-reviewed original and review articles published up to December 2016, using the following keywords: prophylactic transjugular intrahepatic portosystemic shunt, cirrhosis, abdominal surgery. Only human studies were included. To identify additional studies, the reference lists of pertinent studies were searched manually. Studies reporting abdominal surgery in cirrhotic patients with TIPS, but placed for indications other than surgery itself, were excluded. After applying the exclusion criteria, the search yielded only eight single-center studies. The indications, procedural details, success rates, clinical outcomes, complications and limitations of each individual study were studied. Descriptive statistics (percentages, means, median, range) were calculated for each outcome (success, failure, complications) and the same were used to interpret the composite data.

\section{Results}

A total of 8 original studies were identified. These included two case reports from the UK [5] and Italy [6], three case series from the USA [7], Spain [8] and France [9], and three retrospective studies from the USA $[10,11]$ and Canada [12]. A retrospective study from the USA described 25 patients with cirrhosis undergoing abdominal or cardiothoracic surgeries [10]. However, only 4 patients who had prophylactic TIPS before planned abdominal surgery were included [10]. Another retrospective study from the USA described 7 patients who had a TIPS procedure before surgery with the intent to minimize perioperative complications [11]. The retrospective study from Canada compared the clinical outcomes of patients with cirrhosis who underwent TIPS before abdominal surgery with those of the group without TIPS [12]. In this study, only 13 patients had elective TIPS placed before planned abdominal surgery [12]. Data were not reported separately for these 13 patients; hence, we have mentioned the results in the table but have not combined them with those of other studies in order to maintain uniformity in our inclusion and exclusion criteria for this review article.

The results from each individual study are summarized in Table 1.

\section{Patient characteristics}

These studies were small, with the number of subjects undergoing preoperative TIPS varying between 1 and 18 [5- 12]. Only one study had more than 10 subjects [12]. A total of 43 patients across all studies had preoperative TIPS. Thirty-one patients were male and 12 were female. Age for the study cohort varied from as young as 41 years [5] to as old as 80 years [6].
The etiology of liver cirrhosis was alcohol in $47.6 \%(10 / 21)$ of patients, hepatitis $\mathrm{C}$ in $28.6 \%(6 / 21)$, a combination of alcohol and hepatitis $\mathrm{C}$ in $9.5 \%(2 / 21)$, primary biliary cirrhosis in $9.5 \%$ $(2 / 21)$, and cryptogenic in $4.8 \%(1 / 21)$ of patients [5-9,11]. Vinet et al reported $61.1 \%(11 / 18)$ of patients to have a non-alcohol etiology without any further specification [12]. The severity of liver cirrhosis was described using CTP in 7 studies [5-11]. Of 25 patients, $48.0 \%(12 / 25)$ had CTP class A, 36.0\% (9/25) had CTP class B and $16.0 \%(4 / 25)$ patients had CTP class C disease [5-11]. Vinet et al reported a mean CTP score of 7.7 (6-10) for the patients undergoing TIPS and 6.2 (5-9) for the control group [12]. All patients from each study had one or more signs of portal hypertension: ascites [7-12], esophageal varices [5-11], gastric varices $[9,10]$, or gastrointestinal bleeding [5-11].

The baseline patient characteristics from each individual study are summarized in Table 2.

Overall, our study results are reflective of wide heterogeneity in the selected patients considered for elective pre-surgery TIPS, which points to the lack of uniform criteria. We believe that there is a selection bias in all reported studies towards patients expected to do well with or without TIPS followed by surgery. Current guidelines of the American Association for the Study of Liver Diseases suggest caution in placing TIPS in patients with a Model for End-Stage Liver Disease score $>15-18$ or total bilirubin $>4.0 \mathrm{mg} / \mathrm{dL}[13]$. Other absolute contraindications include severe pulmonary hypertension, congestive heart failure, and uncontrolled sepsis. Relative contraindications include anatomical challenges for TIPS placement, coagulopathy and prior episodes of encephalopathy. A multidisciplinary approach should be used, taking into consideration the center's experience, surgeon's expertise and hepatologist's input to allow patient recruitment for TIPS before the planned major abdominal surgery to be safe overall in this high-risk population subgroup.

\section{Timing of TIPS}

The time period between TIPS placement and abdominal surgery was variable and ranged from 1 week [8] to a mean of 2.9 months [9]. Although the hepatic venous pressure reduces immediately after TIPS placement, new hemodynamic equilibrium and its clinical effects take time [14].

Currently, there is no consensus about the optimal timing of surgery after TIPS placement. There are a number of factors that need to be considered, including the type and urgency of abdominal surgery, local expertise, availability of TIPS, and resolution of ascites and varices.

\section{Indication and type of planned surgery}

The most frequent indication for surgery was cancer potentially resectable [5-12]. Surgery would have been the treatment of choice in these patients in the absence of cirrhosis and portal hypertension. These patients underwent a large variety of abdominal surgical procedures, 
Prophylactic TIPS before abdominal surgery $\mathbf{3}$

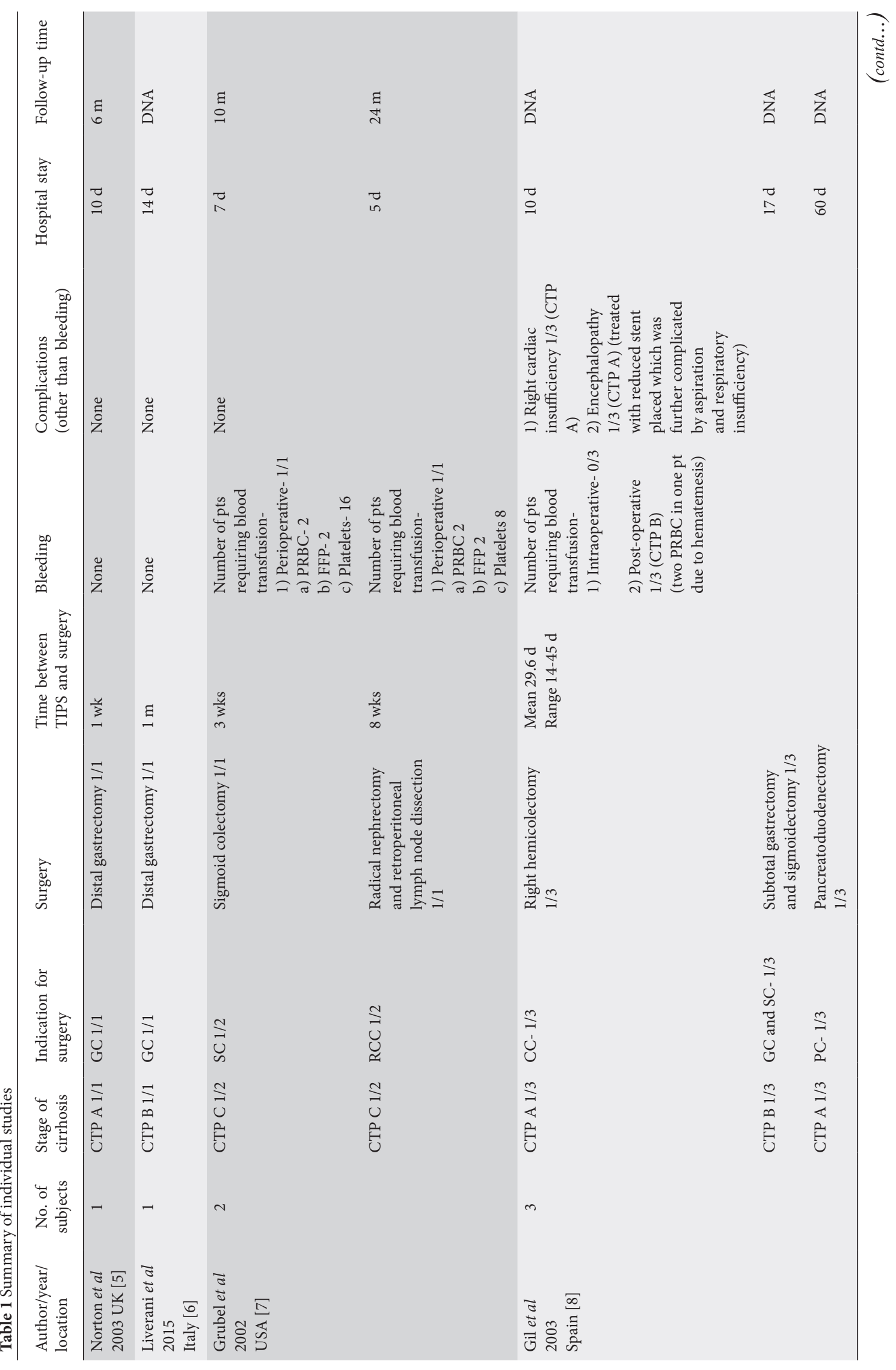




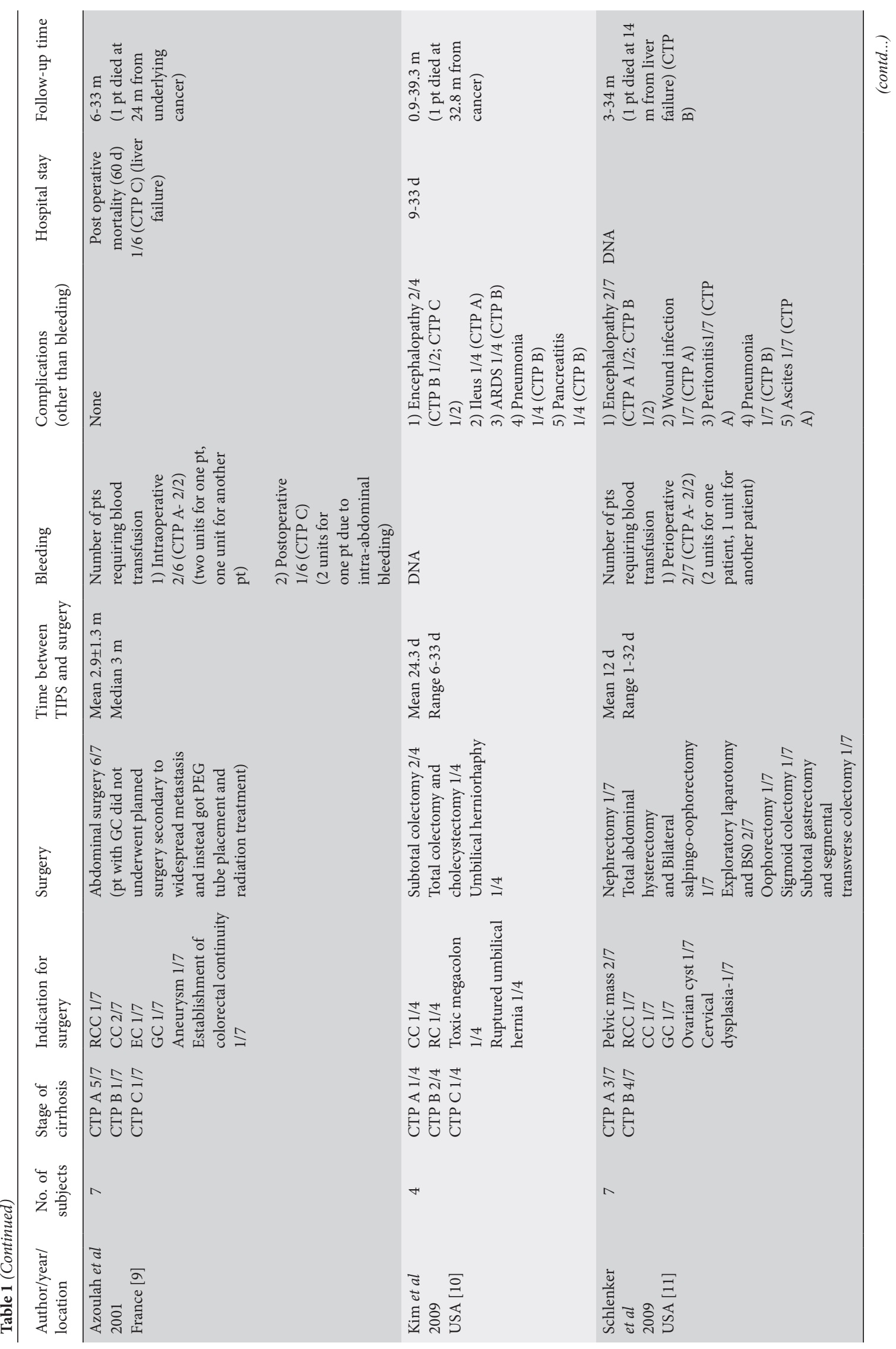




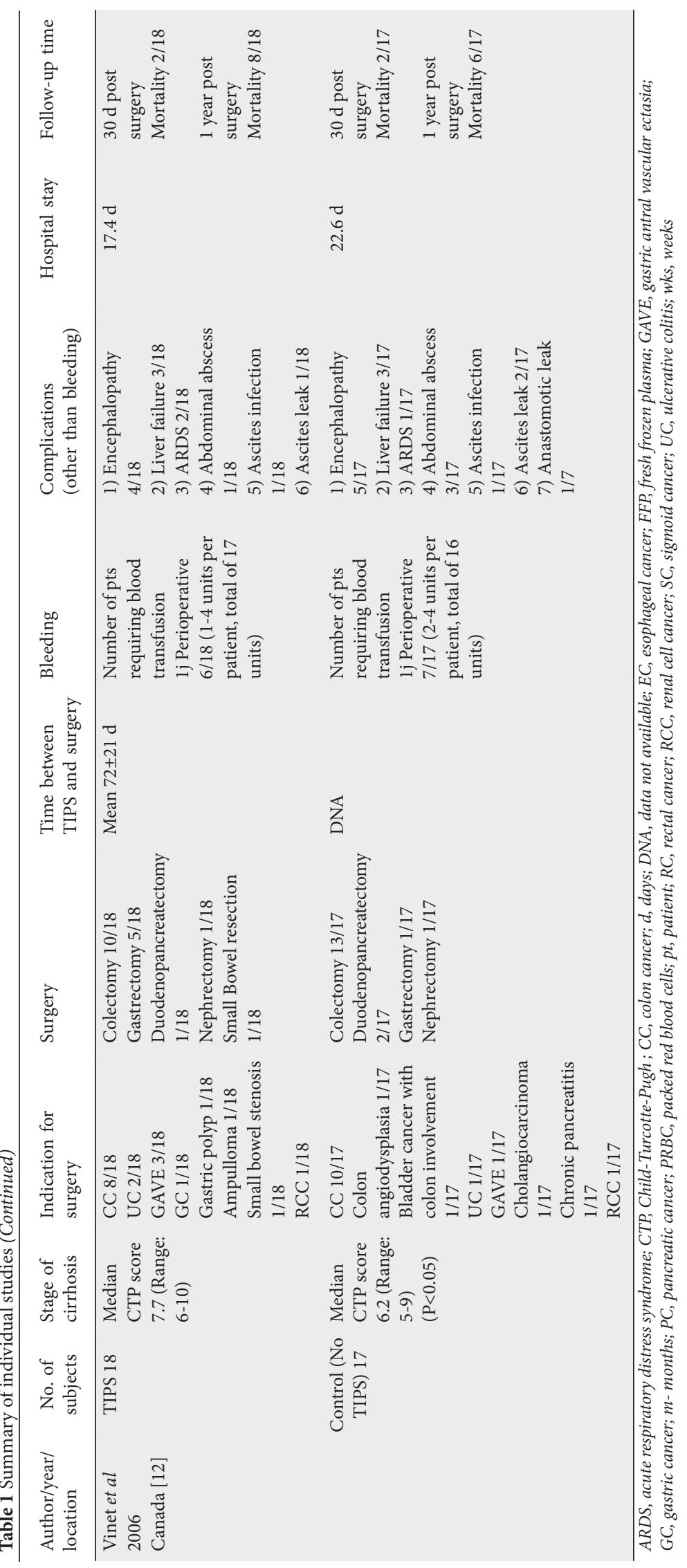


including cholecystectomy [10], umbilical herniorhaphy [10], gastrectomy $[5,6,8,11,12]$, sigmoidectomy $[7,8,11]$, colectomy [8,10-12], nephrectomy $[7,11,12]$, small bowel resection [12], bilateral salpingo-oophorectomy [11], oophorectomy [11], total abdominal hysterectomy [11], pancreato-duodenectomy $[8,12]$ and exploratory laparotomy [11]. The indication and the type of surgery across all individual studies are given in Table 1.

\section{Pre- and post-TIPS hepatovenous portal gradient (HVPG)}

Generally, an HVPG of less than $12 \mathrm{mmHg}$ is targeted for TIPS to be effective. The HVPG was reduced to a range between $6 \mathrm{mmHg}$ and $14 \mathrm{mmHg}$ in the included studies [5-12]. Gil et al reported a patient who had a pre TIPS HVPG of $28 \mathrm{mmHg}$ and a post TIPS HVPG of $6 \mathrm{mmHg}$ [8]. This patient had the largest change in HVPG (22 $\mathrm{mmHg}$ ) among the reported patients. The patient developed right cardiac insufficiency. There is a lack of data to allow an accurate prediction of post-TIPS pressure gradient based on the size of shunt. It is unknown whether TIPS of different sizes should be individualized depending on pre-TIPS pressure gradient, patient's cardiovascular status, body mass index, type of hepatic decompensation and severity of liver disease. Pre- and post-TIPS HVPG values across individual studies have been summarized in Table 3.

The timing of pressure measurement after TIPS placement is also important. In the studies included, the HVPG was measured at the time of TIPS placement; however, it may not be indicative of portal pressures at the time of surgery. A recent study compared portal pressure gradient (PPG) at different times after TIPS placement [15]. The immediate PPG (immediately after TIPS placement) differed significantly from the early

Table 2 Baseline patient characteristics from each individual study

\begin{tabular}{|c|c|c|c|c|c|c|}
\hline $\begin{array}{l}\text { Author/year/ } \\
\text { location }\end{array}$ & $\begin{array}{c}\text { No. of } \\
\text { subjects }\end{array}$ & $\begin{array}{c}\text { Mean } \\
\text { age (range) (years) }\end{array}$ & Sex & Etiology of cirrhosis & $\begin{array}{l}\text { Stage of } \\
\text { cirrhosis }\end{array}$ & Portal hypertension \\
\hline $\begin{array}{l}\text { Norton et al } \\
2003 \\
\text { UK [5] }\end{array}$ & 1 & 41 & Male 1 & Alcohol 1/1 & СТP A $1 / 1$ & $\begin{array}{l}\text { GIB } 1 / 1 \\
\text { EV } 1 / 1\end{array}$ \\
\hline $\begin{array}{l}\text { Liverani et al } \\
2015 \\
\text { Italy [6] }\end{array}$ & 1 & 80 & Female 1 & Hepatitis C $1 / 1$ & СТР B 1/1 & $\begin{array}{l}\text { GIB } 1 / 1 \\
\text { EV } 1 / 1\end{array}$ \\
\hline $\begin{array}{l}\text { Grubel et al } \\
2002 \\
\text { USA [7] }\end{array}$ & 2 & $47(43-51)$ & Male 2 & $\begin{array}{l}\text { Alcohol } 1 / 2 \\
\text { Alcohol+Hepatitis } \\
\text { C } 1 / 2\end{array}$ & CTP C- $2 / 2$ & $\begin{array}{l}\text { GIB } 2 / 2 \\
\text { EV } 2 / 2 \\
\text { Ascites } 2 / 2 \\
\text { SBP } 1 / 2 \\
\text { HE } 1 / 2\end{array}$ \\
\hline $\begin{array}{l}\text { Gil et al } \\
2003 \\
\text { Spain [8] }\end{array}$ & 3 & $64(60-70)$ & $\begin{array}{l}\text { Male } 2 \\
\text { Female } 1\end{array}$ & Hepatitis C $3 / 3$ & $\begin{array}{l}\text { CTP A } 2 / 3 \\
\text { СТP B } 1 / 3\end{array}$ & $\begin{array}{l}\text { GIB } 1 / 3 \\
\text { EV } 3 / 3 \\
\text { Ascites } 1 / 3\end{array}$ \\
\hline $\begin{array}{l}\text { Azoulah et al } \\
2001 \\
\text { France [9] }\end{array}$ & 7 & $56(47-69)$ & $\begin{array}{l}\text { Male } 6 \\
\text { Female } 1\end{array}$ & $\begin{array}{l}\text { Alcohol 5/7 } \\
\text { Hepatitis C 2/7 }\end{array}$ & $\begin{array}{l}\text { CTP A } 5 / 7 \\
\text { CTP B } 1 / 7 \\
\text { CTP C } 1 / 7\end{array}$ & $\begin{array}{l}\text { GIB } 5 / 7 \\
\text { EV } 6 / 7 \\
\text { GV } 1 / 7 \\
\text { Ascites } 3 / 7\end{array}$ \\
\hline $\begin{array}{l}\text { Kim et al } \\
2009 \\
\text { USA [10] }\end{array}$ & 4 & 53 & $\begin{array}{l}\text { Male } 3 \\
\text { Female } 1\end{array}$ & DNA & $\begin{array}{l}\text { CTP A } 1 / 4 \\
\text { CTP B } 2 / 4 \\
\text { CTP C } 1 / 4\end{array}$ & $\begin{array}{l}\text { GIB } 2 / 4 \\
\text { EV } 2 / 4 \\
\text { GV } 1 / 4 \\
\text { Ascites } 2 / 4\end{array}$ \\
\hline $\begin{array}{l}\text { Schlenker et al } \\
2009 \\
\text { USA [11] }\end{array}$ & 7 & $57(48-69)$ & $\begin{array}{l}\text { Male } 3 \\
\text { Female } 4\end{array}$ & $\begin{array}{l}\text { Alcohol } 3 / 7 \\
\text { Alcohol+Hepatitis } \\
\text { C- } 1 / 7 \\
\text { Primary biliary } \\
\text { cirrhosis } 2 / 7 \\
\text { Cryptogenic } 1 / 7\end{array}$ & $\begin{array}{l}\text { CTP А } 3 / 7 \\
\text { СТР В } 4 / 7\end{array}$ & $\begin{array}{l}\text { GIB } 2 / 7 \\
\text { EV } 3 / 7 \\
\text { Ascites } 5 / 7\end{array}$ \\
\hline \multirow[t]{2}{*}{$\begin{array}{l}\text { Vinet et al } \\
2006 \\
\text { Canada[12] }\end{array}$} & TIPS 18 & 58 & $\begin{array}{l}\text { Male } 14 \\
\text { Female } 4\end{array}$ & $\begin{array}{l}\text { Alcohol 7/18 } \\
\text { Non-alcohol 11/18 }\end{array}$ & $\begin{array}{l}\text { Median CTP } \\
\text { score } 7.7 \\
\text { (Range: } 6-10 \text { ) }\end{array}$ & $\begin{array}{l}\text { Ascites } 7 / 18 \\
\text { HE } 3 / 18\end{array}$ \\
\hline & $\begin{array}{c}\text { Control } \\
\text { (No TIPS) } \\
17\end{array}$ & 62 & $\begin{array}{l}\text { Male } 11 \\
\text { Female } 6\end{array}$ & $\begin{array}{l}\text { Alcohol 6/17 } \\
\text { Non-alcohol 11/17 } \\
\text { (P: NS) }\end{array}$ & $\begin{array}{l}\text { Median CTP } \\
\text { score } 6.2 \\
(\text { Range: } 5-9) \\
(\mathrm{P}<0.05)\end{array}$ & $\begin{array}{l}\text { Ascites } 5 / 17 \\
\text { HE } 0 / 17 \\
\text { (P: NS) }\end{array}$ \\
\hline
\end{tabular}

CTP, Child-Turcotte-Pugh; DNA, data not available; EV, esophageal varix; GIB, gastrointestinal bleeding; HE, hepatic encephalopathy; NS, non significant; $S B P$, spontaneous bacterial peritonitis 
PPG (measured after $24 \mathrm{~h}$ ); however, there was no significant difference between proportion of patients with early PPG versus late PPG (measured at $1 \mathrm{month}$ ) for values of $<12 \mathrm{mmHg}$.

\section{Outcome (morbidity)}

\section{Perioperative bleeding}

Minor bleeding. This was defined as $\leq 2$ units of red blood cells (RBCs) in the perioperative period. It is more likely to be the result of the surgery itself and less likely to be the result of portal hypertension.

No bleeding was reported in the cases described by Norton et al and Liverani et al $[5,6]$. Grubel et al reported two patients $(2 / 2$, both CTP C) who each had a transfusion of 2 units of RBCs and 2 units of fresh frozen plasma [7]. In the study by Gil et al, none of the subjects $(0 / 3)$ required intraoperative transfusion, though one patient (CTP B) did require 2 units of RBCs in the postoperative period because of hematemesis [8]. In another study, two patients (2/6, both CTP A) received intraoperative transfusion and one patient (1/6, CTP C) required 2 units of RBCs in the postoperative period because of intra-abdominal bleeding [9]. Schlenker et al reported the requirement of 1 unit of RBCs for one patient and 2 units for another patient of 7 study patients (2/7, both CTP A) [11]. Of eight patients with minor bleeding, four were CTP A, one was CTP B and three were CTP C class.

Major bleeding. This was defined as the need for $>2$ units of RBCs in the perioperative period. This amount of bleeding is more likely to be attributable to persistent portal hypertension. None of the patients $(0 / 20)$ from studies had major abdominal bleeding in the perioperative post-surgery period [5-9,11].

Vinet et al reported that the number of transfusions and the total quantity needed were lower for patients with TIPS compared to those without TIPS undergoing abdominal surgery [12]. Six of 18 patients in the TIPS group required 1 to 4 units of RBCs, whereas 7 of 17 patients in control group required between 2 and 4 units [12]. The authors did not report data specifically for patents with prophylactic TIPS.

\section{Wound healing}

Ascites can potentially delay wound healing and may even increase the risk for peritonitis and wound infection. TIPS placement seems to lower the risk of these complications. Among the studies evaluated [5-11], Schlenker et al reported two patients, one with new ascites and wound infection (related to portal hypertension) and the other developing a fecal fistula with localized peritonitis post surgery (unrelated to portal hypertension) [11]. Both of these patients improved with antibiotics and drainage. In composite, only one (CTP-A) of 24 patients (4.2\%) had trouble with wound healing post surgery.

\section{Encephalopathy}

TIPS placement can potentially worsen hepatic encephalopathy secondary to shunting of blood with toxins to the brain. In our study cohort [5-11], a total of 5 patients $(5 / 24)$ were reported to develop hepatic encephalopathy post surgery $[8,10,11]$. Two of these patients had changes in portosystemic gradient (PSG) of $22 \mathrm{mmHg}$ [8] and $13 \mathrm{mmHg}$ [11] post TIPS, whereas the data for the other three patients $[10,11]$ were not available. Currently, we lack prediction models for the expected change in PSG with different sizes of shunt. In addition, other factors, such as the pre-TIPS severity of liver disease, also play a role. Of 5 patients with hepatic encephalopathy, 2 were CTP A, 2 were CTP B, and one was CTP C class $[8,10,11]$. Careful evaluation of each individual patient with cirrhosis is essential to determine the safety of TIPS for these patients.

\section{Cardiac complications}

Cardiac complications post TIPS are in most cases seen in patients who have a pre-existing cardiovascular disease that worsens post TIPS as a result of volume overload. In our cohort [5-11], one patient (1/24) (CTP A) developed rightheart failure post TIPS [8]. As explained above, this was likely due to an inadvertent decrease in PSG post TIPS and the patient consequently underwent a repeat procedure with a smaller stent size. None of the other studies reported this complication [5-7,9-11]. The remainder of the complications secondary to surgery (unrelated to portal hypertension) are summarized in Table 1.

Composite portal hypertension-related morbidity (complication) events for our study cohort were 8 among 12 CTP A class patients, 3 among 8 CTP B class patients, and 4 among 4 CTP C class patients. All of these, as mentioned above, were successfully managed conservatively with zero mortality.

\section{Outcome (mortality)}

Zero mortality was observed in patients with TIPS in the perioperative period following abdominal surgery [5-11]. Two deaths from liver failure at 5 weeks [9] and 14 months [11] in CTP C and CTP B class patients, respectively, were reported. Mortality from non-liver-related causes has been summarized in Table 1.

\section{Concluding remarks}

Prophylactic TIPS placement for cirrhotic patients scheduled for abdominal surgery has been sought as a viable option to improve surgical outcomes in this population subset. The evidence for its safety and its real-world impact on perioperative morbidity is still sparse. Prophylactic TIPS placement was successful in preventing mortality secondary to abdominal surgery in cirrhotic patients. No major abdominal bleeding was noted. One patient had poor wound healing post surgery $(4.2 \%)$, one had right heart failure $(4.2 \%)$, and five developed hepatic encephalopathy $(20.8 \%)$. No uniform trend was noted for the timing of abdominal surgery post TIPS. More evidence is needed to optimize the selection of stent size 
Table 3 Hepatovenous portal gradient (HVPG) pre and post transjugular intrahepatic portosystemic shunt (TIPS) for patients from each individual study

\begin{tabular}{|c|c|c|c|c|}
\hline $\begin{array}{l}\text { Author/year/ } \\
\text { location }\end{array}$ & Number of subjects & HVPG pre TIPS $(\mathrm{mmHg})$ & HVPG post TIPS (mmHg) & Change in HVPG (mmHg) \\
\hline $\begin{array}{l}\text { Norton et al } 2003 \\
\text { UK [5] }\end{array}$ & 1 & 16 & 12 & 4 \\
\hline $\begin{array}{l}\text { Liverani et al } 2015 \\
\text { Italy [6] }\end{array}$ & 1 & 28 & 12 & 16 \\
\hline Grubel et al 2002 & 2 & 17 & 8 & 9 \\
\hline \multirow{4}{*}{$\begin{array}{l}\text { Gil et al } 2003 \\
\text { Spain }[8]\end{array}$} & & 26 & 14 & 12 \\
\hline & 3 & 22 & 7 & 15 \\
\hline & & 20 & 7 & 13 \\
\hline & & 28 & 6 & 22 \\
\hline $\begin{array}{l}\text { Azoulah et al } 2001 \\
\text { France [9] }\end{array}$ & 7 & Mean $18 \pm 5$ & Mean $9 \pm 5$ & Mean 9 \\
\hline $\begin{array}{l}\text { Kim et al } 2009 \\
\text { USA [10] }\end{array}$ & 4 & NA & NA & NA \\
\hline $\begin{array}{l}\text { Schlenker et al } 2009 \\
\text { USA [11] }\end{array}$ & 7 & $\begin{array}{c}\text { Mean } 15.2 \\
\text { (Range: 9-22) }\end{array}$ & $\begin{array}{c}\text { Mean } 7.4 \\
\text { (Range: } 4-10)\end{array}$ & $\begin{array}{c}\text { Mean } 6.8 \\
\text { (Range: } 2-13 \text { ) }\end{array}$ \\
\hline \multirow{2}{*}{$\begin{array}{l}\text { Vinet et al } 2006 \\
\text { Canada [12] }\end{array}$} & TIPS- 18 & Mean $21.4 \pm 3.9$ & Mean $8.4 \pm 3.4$ & Mean 13 \\
\hline & Control (No TIPS) 17 & Not applicable & Not applicable & Not applicable \\
\hline
\end{tabular}

to prevent an inadvertent decrease in HVPG and consequently reduce the complication rate. Overall, the decision regarding prophylactic TIPS placement for cirrhotic patients undergoing abdominal surgery needs individualization to allow its safe use, with concomitant improvement in perioperative morbidity.

\section{References}

1. Aranha GV, Greenlee HB. Intra-abdominal surgery in patients with advanced cirrhosis. Arch Surg 1986;121:275-277.

2. Mansour A, Watson W, Shayani V, Pickleman J. Abdominal operations in patients with cirrhosis: still a major surgical challenge. Surgery 1997;122:730-735.
3. Friedman LS. The risk of surgery in patients with liver disease. Hepatology 1999;29:1617-1623.

4. Boyer TD, Haskal ZJ; American Association for the Study of Liver Diseases. The role of transjugular intrahepatic portosystemic shunt in the management of portal hypertension. Hepatology 2005;41:386-400.

5. Grübel P, Pratt DS, Elhelw T. Transjugular intrahepatic portosystemic shunt for portal decompression before abdominal and retroperitoneal surgery in patients with severe portal hypertension. J Clin Gastroenterol 2002;34:489-490.

6. Gil A, Martínez-Regueira F, Hernandez-Lizoain JL, et al. The role of transjugular intrahepatic portosystemic shunt prior to abdominal tumoral surgery in cirrhotic patients with portal hypertension. Eur J Surg Oncol 2004;30:46-52.

7. Azoulay D, Buabse F, Damiano I, et al. Neoadjuvant transjugular intrahepatic portosystemic shunt: a solution for extrahepatic 
abdominal operation in cirrhotic patients with severe portal hypertension. J Am Coll Surg 2001;193:46-51.

8. Norton SA, Vickers J, Callaway MP, Alderson D. The role of preoperative TIPSS to facilitate curative gastric surgery. Cardiovasc Intervent Radiol 2003;26:398-399.

9. Liverani A, Solinas L, Di Cesare T, et al. Preoperative trans-jugular porto-systemic shunt for oncological gastric surgery in a cirrhotic patient. World J Gastroenterol 2015;21:997-1000.

10. Kim JJ, Dasika NL, Yu E, Fontana RJ. Cirrhotic patients with a transjugular intrahepatic portosystemic shunt undergoing major extrahepatic surgery. J Clin Gastroenterol 2009;43:574-579.

11. Schlenker C, Johnson S, Trotter JF. Preoperative transjugular intrahepatic portosystemic shunt (TIPS) for cirrhotic patients undergoing abdominal and pelvic surgeries. Surg Endosc
2009;23:1594-1598.

12. Vinet E, Perreault P, Bouchard L, et al. Transjugular intrahepatic portosystemic shunt before abdominal surgery in cirrhotic patients: a retrospective, comparative study. Can J Gastroenterol 2006;20:401-404.

13. Boyer TD, Haskal ZJ. The role of transjugular intrahepatic portosystemic shunt (TIPS) in the management of portal hypertension: Update 2009. AASLD practice guidelines.

14. Gaba RC, Parvinian A. How quickly does ascites respond to TIPS? Clinical follow-up of a cohort of eighty patients. Diagn Interv Radiol 2014;20:364.

15. Silva-Junior G, Turon F, Baiges A, et al. Timing affects measurement of portal pressure gradient after placement of transjugular intrahepatic portosystemic shunts in patients with portal hypertension. Gastroenterology 2017;152:1358-1365. 